\title{
Job Selection Preferences Of Business Students
}

Charalambos L. Iacovou (E-mail: charles.iacovou@mba.wfu.edu), Wake Forest University

Larry Shirland (E-mail: larry.shirland@uvm.edu), University of Vermont

Ronald L. Thompson (E-mail: ron.thompson@mba.wfu.edu), Wake Forest University

\begin{abstract}
To assess the job selection preferences of business students, two hundred forty one undergraduate and MBA students participated in a survey evaluating the importance of 20 job attributes. Overall, the students rated growth potential, benefits package, job responsibility and variety as the most important attributes when pursuing an employment opportunity. The results indicate that graduate business students are more concerned with work culture, flexibility and ease of commute and less concerned with company recognition compared to undergraduates. The findings also show that work culture seems to be especially relevant to female MBA students, while geographical location seems to be least relevant to male MBA students. Our results suggest that, to be effective with their recruitment efforts, employers and placement professionals must take into account both key desirable job attributes and the unique needs of their targeted business student sub-populations.
\end{abstract}

\section{Introduction}

$\mathscr{Q}$ nderstanding why students prefer one company's employment offer over another is important for several reasons. By understanding the students' priorities, corporate recruiters can effectively assess whether there is a good fit between their organizations and specific candidates, and can better tailor their offers to increase their attractiveness to them. University placement professionals can also benefit from such an understanding. It enables them to tailor their on-campus recruiting schedules by inviting potential employers with positions that closely match their students' preferences.

To assist recruiters and placement personnel in understanding student preferences, we conducted a survey asking both undergraduate business and MBA students at a public university to express their job selection preferences, by evaluating 20 job attributes. ${ }^{1}$ Our study also examined the effects of two demographic factors (gender and status [undergraduate vs. graduate]) on such preferences.

This study builds upon an extensive stream of research on student job preferences. However, our empirical methods were carefully selected to address shortcomings that are common in earlier studies. Unlike previous work utilizing short, incomplete lists of job attributes (e.g., Butler, Sanders \& Whitecotton 2000), our survey included 20 job attributes (based on an extensive literature review of prior work); instead of using univariate statistics, which are inappropriate for assessing related, multi-attribute job preferences, (e.g. McGinty \& Reitsch 1992) we used multivariate analyses yielding more accurate results; and instead of utilizing simple rating methods to derive the students' evaluations, which tend to be ineffective with large attribute sets (Van der Pligt, de Vries, Manstead \& Harreveld 2000), we employed an innovative evaluation method that minimizes the cognitive burden on individuals assessing a large set of attributes (Shirland, Jesse, Thompson \& Iacovou 2002). For these reasons, we believe that our results are more reliable than those of previous studies.

Our findings have significant practical implications. While corporate recruiters will be well-advised to package their offers so that they take into account the students' most preferred job attributes (such as growth potential, benefits package and job responsibility), our results indicate the existence of significant differences across 
student sub-populations. While our findings confirm the existence of a direct student status effect on preferences (as identified by prior research), they also indicate that that a gender effect is likely to be indirect and be moderated by student status. This important discovery sheds new light on prior work and has important consequences for management and research.

\section{Research On Job Attribute Preferences Of Business Students}

Over the past few decades, many researchers have investigated factors influencing job selection decisions. Several of them have focused on preferences for certain categories of students, such as accounting students (Bundy \& Norris 1991, Rebele, Apostolou, Buckless, Hassell, Paquette \& Stout 1998, Rebele, Stout \& Hassell 1991) and information systems students (Robbins 1996). Some have focused on the preferences of recruiters (Simon \& Kedslie 1997). Others have looked for differences between perceptions of students before and after a decision on a job offer (Turban, Eyring \& Campion 1993), between students and recruiters (Butler et al. 2000, Kirsch, Leathers \& Snead 1993), and between students and working professionals (Carcello, Copeland, Hermanson \& Turner 1991). Finally, some researchers have exclusively focused on specific attributes, such as pay preferences (Cable \& Judge 1994), and on specific individual differences, such as gender (Tolbert \& Moen 1998).

This long stream of inquiry has produced some interesting results (see Table 1 for a summary of some frequently cited studies). A few job attributes are consistently ranked as the most important ones in various studies. Advancement potential appears in all top-five lists of the summarized studies; type of work (interesting/challenging) appears in five (out of six); and job security, salary, and quality of coworkers appear in three. Other attributes (such as location, social responsibility, type of firm, etc), however, seem to be more transient and often receive different rankings across multiple studies. While the consistent presence of the select "core" attributes across studies provides reassurance about their validity, the lack of consistency in the other attributes' ratings is somewhat troubling.

Table 1: Previous Studies On Job Attribute Preferences Of Business Students

\begin{tabular}{|l|c|l|l|l|}
\hline \multicolumn{1}{|c|}{ Study } & $\begin{array}{l}\text { Number of } \\
\text { Attributes } \\
\text { Evaluated }\end{array}$ & \multicolumn{1}{|c|}{ Five Most Important Attributes } & $\begin{array}{c}\text { Gender } \\
\text { Effect }\end{array}$ & $\begin{array}{c}\text { Status } \\
\text { Effect }\end{array}$ \\
\hline $\begin{array}{l}\text { Carpenter \& } \\
\text { Strawser (1970) }\end{array}$ & 11 & $\begin{array}{l}\text { Nature of work, Opportunities for advancement, Salary, Working } \\
\text { conditions, Job security }\end{array}$ & $\begin{array}{l}\text { Not } \\
\text { reported }\end{array}$ & $\begin{array}{l}\text { Not } \\
\text { reported }\end{array}$ \\
\hline $\begin{array}{l}\text { Bundy \& Norris } \\
(1991)\end{array}$ & 35 & $\begin{array}{l}\text { Job security, Challenging and Interesting work, Advancement } \\
\text { potential, Employer-paid health, Personalities of Supervisors and } \\
\text { Co-workers }\end{array}$ & Yes & $\begin{array}{l}\text { Yes } \\
\text { (age) }\end{array}$ \\
\hline $\begin{array}{l}\text { McGinty \& } \\
\text { Reitsch (1992) }\end{array}$ & 5 & Location, Advancement, Social responsibility, Interest, Salary & $\begin{array}{l}\text { Not } \\
\text { reported }\end{array}$ & $\begin{array}{l}\text { Not } \\
\text { reported }\end{array}$ \\
\hline $\begin{array}{l}\text { Turban et al. } \\
(1993)\end{array}$ & 11 & Type of work, Advancement, Co-workers, Company, Security & No & $\begin{array}{l}\text { Not } \\
\text { reported }\end{array}$ \\
\hline $\begin{array}{l}\text { Browne (1997) } \\
\text { Brownes }\end{array}$ & 7 & $\begin{array}{l}\text { Interesting or challenging work, Salary, Sense of accomplishment, } \\
\text { Chance of promotion, Stimulating/competent coworkers }\end{array}$ & $\begin{array}{l}\text { Yes } \\
\text { reported }\end{array}$ \\
\hline $\begin{array}{l}\text { Butler et al. } \\
(2000)\end{array}$ & 6 & $\begin{array}{l}\text { Compensation package, Opportunities for Advancement/Job } \\
\text { stability, Type of Firm, Flex-Time, Work environment }\end{array}$ & $\begin{array}{l}\text { Not } \\
\text { reported }\end{array}$ & $\begin{array}{l}\text { Not } \\
\text { reported }\end{array}$ \\
\hline
\end{tabular}

We assert that the apparent lack of consistency in the rankings of some of the job attributes is caused by at least two reasons: (1) the use of diverse (and sometimes inappropriate) empirical methods in surveying the students and (2) natural variations in the preferences of students depending on the timing of the survey inquiry, the students' recruitment status, and their specific socio-demographic traits.

In terms of research methods, investigators have employed both diverse lists of attributes to elicit preferences --ranging from 5 items in McGinty \& Reitsch (1992) to 35 in Bundy \& Norris (1991) - and varied evaluation techniques to prioritize such preferences --ranging from simple ratings in Bundy \& Norris (1991), to 
rankings in Turban et al. (1993) and scenario selection in McGinty \& Reitsch (1992)—. The use of such varied methods can partially account for the diversity in findings as different evaluation procedures are likely to produce heterogeneous results (Pöyhönen and Hämäläinen 2001). Inconsistency in results may be also be caused by the unreliability of some methods. For example, simple ranking and rating methods have been shown to be ineffective when evaluating large attribute sets (Flynn, Sakakibara, Schroeder, Bates \& Flynn 1990). Research indicates that by asking respondents to assess each of a large number of job attributes simultaneously (e.g. Bundy \& Norris 1991), excessive information processing requirements are placed upon evaluators. This can lead to cognitive overload and respondent fatigue, and can thus produce unreliable results (Van der Pligt et al. 2000). To address the threats that may be raised by the use of such simplistic approaches, we used a comprehensive job attribute list and a novel, sophisticated evaluation technique to derive the students' preferences in this study.

In terms of naturally-occurring variation in student preferences, we expect that at least three effects are causing some differences across studies. Firstly, the timing of the study (year of survey) is likely to impact the preferences of the students, as economic conditions and significant world events (such as the recent accounting scandals, major crises in certain industries due to the 2001 terrorist attacks, etc.) are likely to influence perceptions and values (Tolbert \& Moen 1998). Secondly, the timing of the survey's administration relative to a respondent's job searching process is likely to affect the results. This is because a job candidate's preferences are likely to be altered as the process progresses due to experience and newly acquired knowledge (Turban et al. 1993). Finally, differences in findings are likely to be partially explained by the diversity of the student population itself. Individual characteristics (such as age, gender, marital status, and work experience) are likely to influence job preferences. Extensive research has shown that two such characteristics --gender and experience-- significantly impact the students' preferences (Tolbert \& Moen 1998).

Due to the changing, diverse preferences of business students, there is a need for a systematic and periodic survey of such preferences --using reliable methods-- to spot true differences in the evaluations of students. This will enable organizations and placement offices to tailor their recruitment efforts by separating real trends in the core attribute preferences from temporary blips. Our study aims to achieve this by reliably assessing the students' evaluations of job qualities as identified by prior work. Because of the important effects of gender and experience on such evaluations (see Table 1), their impact was explicitly considered in our study. A discussion of their hypothesized effects follows.

Extensive literature empirically demonstrates that a student's gender influences job preferences (Browne 1997, Konrad \& Langton 1991, Lathan, Ostrowski, Pavlock \& Scott 1987, Tolbert \& Moen 1998). In a recent metaanalysis of this literature, Konrad, Ritchie, Lied \& Corrigall (2000) found strong evidence of gender differences. In their review of 242 studies between 1970 and 1998, they found a gender difference in 33 out of 40 job attributes. They concluded that women are more likely to endorse items like opportunity to assist others, good supervision and short commute more than men (who typically valued high earnings and power in their work). Given the extensive evidence supporting gender differences, we anticipate that:

H1: Female business students will rate job attributes differently than male students.

In terms of experience, students searching for their first professional job (which is the typical scenario for most undergraduate students) are likely to have a different set of uncertainties, expectations and preferences about the job search process compared to more mature students possessing significant work experience (such as MBA students returning to graduate school after working for several years). Empirical research seems to suggest that such differences are likely to influence job attribute ratings (Bundy \& Norris 1991, Carcello et al. 1991, Cotterman 1991). Given this, we expect that:

H2: Graduate business students will rate job attributes differently than undergraduate students. 


\section{Research Methodology}

\subsection{Measurement Instrument}

The instrument for this study consisted of a questionnaire containing an evaluation task. The first part of the instrument explained the purpose of the study and provided instructions for completing the task. The evaluation task required the participant to assess twenty job attributes in terms of their perceived importance. Definitions of the job attributes were included in the questionnaire (see Appendix 1 for the list of the attributes and their dimensions).

Job characteristics were evaluated in triads. Each respondent rated the relative importance of each of the items in the triad by comparing them independently of other triads (see Appendix 2 for a partial description of the instructions provided in the questionnaire). ${ }^{2}$ This approach improves the quality of multi-attribute judgments as it reduces the threat of a cognitive overload that is frequently experienced in simultaneous comparisons of large attribute sets (Shirland et al. 2002). To convert the triad comparisons into ratings, a goal-programming model with an objective function that minimizes the least-squares errors from the "ideal" set of weights was utilized (for a detailed description of the methodology used, see Shirland et al. 2002).

To produce the list of the attributes that were included in the questionnaire, a multiple-step process was pursued. To generate a preliminary list, we reviewed relevant literature and conducted a focus group with four students. This list was reviewed and fine-tuned by four experts (two researchers and two career management consultants). The revised list was pre-tested with another five students to assess its clarity and completeness. Based on the feedback, a final list of 20 items was generated.

\subsection{Sample}

All participants in this study were business students at a major public university in the United States. Two hundred forty one (241) completed the questionnaire. The survey was administered during the initial stages of their job search process. On average, it took students about 15 minutes to complete it. Although participation in this study was optional and no compensation (other than a summary of the results) was offered, of all the students asked to participate only one declined to do so. This is not surprising, as research indicates that job attribute evaluation tasks are perceived to be both important and relevant by students (Bundy \& Norris 1991, Butler et al. 2000, Carpenter \& Strawser 1970).

One hundred fifty nine (66\%) of the participants were male and $82(34 \%)$ were female. Forty-five (18.7\%) of them were MBA students, while the other one hundred and ninety-six (81.3\%) were full-time undergraduate students. The undergraduate students in this study were 19-21 years of age and had no or very little work experience. In contrast, the graduate students were primarily working professionals with an average of approximately six years of work experience.

In the survey, the participants were asked to report their level of interest in the study's subject and the perceived ease of the task. The average rating for the importance of job attributes to the respondent was 6.1 (out of 7) with a standard deviation of 1.1; the average rating for the perceived ease of completing the questionnaire was 4.9 with a standard deviation of 1.8. This indicates that the topic of the study was perceived to be relevant, and the task was perceived to be moderately challenging by the participants.

\subsection{Statistical Analysis}

To examine the impact of the independent variables on the students' ratings, a repeated-measures MANCOVA test was conducted. MANCOVA was selected (instead of MANOVA) as we felt it was important to include the students' self-reported level of interest in the study's subject as a covariate in our analysis. We believed that participants with low interest in the subject would spend less time completing the tasks, be less discriminating in their ratings and be less likely to be satisfied with their involvement in this study. 

participants:

The MANCOVA analysis ${ }^{3}$ examined the effects of the following independent factors on the ratings of the

- $\quad$ Gender of the participant;

- $\quad$ Student Status of the participant (graduate versus undergraduate); and

- Interest in the subject of the study as indicated by the importance rating of the participants.

According to the results of the multivariate analysis (see Table 2), the direct effect of Student Status and the interaction effect of Gender by Student Status were found to be statistically significant. The direct effect of Gender was not found to be significant. Based on this, $\mathrm{H} 1$ is not supported, while $\mathrm{H} 2$ is. To identify the precise impact of the above two significant effects on the students' evaluations, univariate ANOVA tests were conducted. The results of this analysis are discussed in the next section.

Table 2: MANCOVA Results

\begin{tabular}{|c|c|c|c|}
\hline Factor & $\begin{array}{l}\text { Pillai's } \\
\text { Trace }\end{array}$ & $\mathbf{F}^{\#}$ & Sig. (p) \\
\hline Intercept & .992 & 1381.216 & .000 \\
\hline Interest (Covariate) & .071 & .841 & .656 \\
\hline Gender & .092 & 1.114 & .338 \\
\hline Student Status & .126 & 1.592 & .060 \\
\hline Gender * Student Status & .134 & 1.711 & .036 \\
\hline
\end{tabular}

Note: ${ }^{\#}$ Degrees of Freedom: $(19,210)$

\section{Findings}

\subsection{Overall Evaluation Of Job Attributes}

The ratings of the twenty job attributes as assigned by the participants are presented in Table 3. Growth potential was rated as the most important criterion. In addition, benefits, job responsibility, job variety/complexity and work flexibility rounded out the top five. Significant similarities exist between our top-5 five list and those of prior studies. Growth potential -which was ranked as the most important job attribute in our study - has been ranked in the top 10\% of attribute lists for most studies involving business students (Bundy \& Norris, 1991, McGinty \& Reitsch 1992, Turban et al. 1993). Nature of work (which in our study was split into job responsibility, variety and flexibility), when included in the attribute set, is typically ranked in the top four attributes (see Table 1). Finally, benefits (representing health insurance, etc) were also identified by previous studies (Bundy \& Norris, 1991, Butler et al. 2000) as important.

One attribute that received different treatment by the students in our study (compared to previous studies) is stock options. This item was ranked $6^{\text {th }}$ in our study. In contrast, the availability of a stock option/ownership program was ranked 20th out of 23 criteria in a previous study (Phillips, Phillips \& Cappel 1994). We believe that this difference is due to the timing of the questionnaire's administration. The data for this study were collected just prior to the 2001 technology bust. During the period from 1999-2001, the popular press reported many examples of young individuals becoming rich through stock ownership in fast-growing technology companies, which increased the general interest in stock option plans. If the same list of attributes were ranked by respondents today (following the early 2000's technology bust), we would anticipate that stock option programs would be ranked much lower. This observation clearly supports the need for regular surveying of the students' preferences using reliable methods. 
Table 3: Overall Ratings Of Job Attributes

\begin{tabular}{|l|c|c|}
\hline \multicolumn{1}{|c|}{ Job Attribute } & $\begin{array}{c}\text { Mean } \\
\text { Rating }\end{array}$ & $\begin{array}{c}\text { Standard } \\
\text { Deviation }\end{array}$ \\
\hline 1. Growth Potential & 8.5 & 3.3 \\
2. Benefits & 7.6 & 3.0 \\
3. Job Responsibility & 6.9 & 2.2 \\
4. Job Variety/Complexity & 6.4 & 2.0 \\
5. Work Flexibility & 6.3 & 2.3 \\
6. Stock Options & 5.9 & 3.0 \\
7. Work Style & 5.7 & 1.7 \\
8. Geographical Region & 5.7 & 2.9 \\
9. Work Culture & 5.5 & 2.7 \\
10. Professional Dev. Programs & 4.7 & 2.8 \\
11. Organization Type & 4.6 & 2.3 \\
12. Travel Opportunities & 4.2 & 2.4 \\
13. Company Recognition & 4.2 & 2.6 \\
14. Ease of Commute & 4.0 & 2.4 \\
15. Training Classes & 3.9 & 2.3 \\
16. Company Size & 3.5 & 2.1 \\
17. City Size & 3.5 & 2.4 \\
18. Travel Requirements & 3.4 & 1.8 \\
19. Social Responsibility & 3.2 & 2.3 \\
20. Environmental Reputation & 2.4 & 2.4 \\
\hline
\end{tabular}

\subsection{Gender Effect}

Contrary to our first hypothesis, the results did not confirm a direct gender effect, which has been found in other studies (Browne 1997, Bundy \& Norris 1991, Konrad \& Langton 1991, Tolbert \& Moen 1998). Our finding is, however, consistent with that of Turban et al. (1993) who also did not find such effect. Three reasons can be offered to help explain this result.

Firstly, it is possible that no direct gender effect was found because our list of job attributes was "gender neutral." Several studies that found a significant direct effect included gender-sensitive items in their lists. For example, the four attributes where Bundy \& Norris (1991) observed a gender difference were office support, employer-paid pregnancy leave, after-hours social activities, and on-premise day care facilities, which are likely to affect men differently from women.

A second reason could be the statistical approach that was used to analyze the data set. Several studies where direct gender effects have been found used univariate statistics only. In contrast, in this study (and in Turban et al. 1993 as well) multivariate analysis was employed, where all effects were considered simultaneously. As a multivariate analysis is more appropriate for such sets (and is less likely to lead to false findings), we believe that our findings are likely to be robust and more accurate than those reported in previous studies.

A third reason may be the timing of our study. In our opinion, the female gender role has changed significantly since the 1970's when job attribute preference studies began to receive attention; research suggests that there is now a much greater degree of convergence in job preferences (Tolbert \& Moen 1998). Moreover, we believe that gender differences are less likely to be found in specific subpopulations of students. Specifically, we expect that such differences are less likely to occur in non-expert populations (such as undergraduate students) as their members tend to provide homogeneous, socially expected "canned" responses. As Bottomley, Doyle \& Green (2000, p. 511) suggest, gender effects are likely to be found in expert populations (such as graduate students) as they tend to provide truly personal evaluations: 
Experts are not only more knowledgeable about what is important (to themselves), but also more likely to hold these opinions with greater conviction than novices.

The existence of a significant interaction effect in our findings (between gender and student status) is consistent with the above argument. As Table 4 indicates, geographical region and work culture were impacted by this effect. More specifically, inexperienced undergraduate men and women ranked these two job attributes more similarly than did their graduate counterparts. This suggests that while a gender effect may be at play, it is moderated by the student status and is likely to be more pronounced in graduate business student groups than in undergraduate ones.

Table 4: Ratings By Student Status And Gender

\begin{tabular}{|l|c|c|c|c|}
\hline \multicolumn{1}{|c|}{ Job Attribute } & $\begin{array}{c}\text { Female } \\
\text { Undergraduate }\end{array}$ & $\begin{array}{c}\text { Female } \\
\text { Graduate }\end{array}$ & $\begin{array}{c}\text { Male } \\
\text { Undergraduate }\end{array}$ & Male Graduate \\
\hline Benefits & 8.0 & 6.4 & 7.6 & 6.3 \\
City Size & 3.3 & 3.1 & 3.7 & 2.0 \\
Company Recognition & 4.1 & 4.2 & 4.4 & 2.1 \\
Company Size & 3.7 & 2.1 & 3.6 & 3.0 \\
Ease of Commute & 3.8 & 5.2 & 3.9 & 5.4 \\
Environmental Reputation & 2.4 & 1.5 & 2.5 & 1.8 \\
Geographical Region* & 5.2 & 6.0 & 6.2 & 3.6 \\
Growth Potential & 8.8 & 7.4 & 8.5 & 8.3 \\
Job Responsibility & 7.0 & 7.2 & 6.7 & 8.0 \\
Job Variety/Complexity & 6.5 & 7.0 & 6.1 & 7.5 \\
Organization Type & 4.5 & 3.8 & 4.8 & 5.4 \\
Professional Dev. Programs & 4.7 & 6.1 & 4.2 & 5.8 \\
Social Responsibility & 3.3 & 3.0 & 3.3 & 3.3 \\
Stock Options & 5.4 & 4.6 & 6.5 & 6.1 \\
Training Classes & 4.4 & 5.0 & 3.5 & 5.0 \\
Travel Opportunities & 4.4 & 3.4 & 4.4 & 3.2 \\
Travel Requirements & 3.8 & 2.6 & 3.3 & 2.6 \\
Work Culture** & 5.0 & 8.8 & 5.4 & 7.1 \\
Work Flexibility & 6.2 & 7.3 & 6.1 & 7.7 \\
Work Style & 5.6 & 5.4 & 5.7 & 6.0 \\
\hline Not: & & & \\
\hline
\end{tabular}

Note: $* *=p<.05 ; *=p<.10$

\subsection{Experience Effect}

In terms of the direct experience effect, four job characteristics were significantly affected by it: company recognition, ease of commute, work culture and work flexibility (see Table 5 for a complete comparison of the ratings by undergraduate and graduate students). Undergraduate students rated company recognition as significantly more important than graduate students. In contrast, MBA students rated work culture, flexibility and ease of commute as being more important than undergraduate students.

The differences suggest that the experienced working professionals were more likely to emphasize factors that would help them balance work and family life and were more sensitive to how work culture could impact their overall quality of life. In contrast, the undergraduate students were more concerned with securing a job with a company that had strong brand recognition that would hopefully provide them with credibility (through association) for future career advancement. This finding is consistent with prior empirical research (Judge \& Bretz 1992). 
Table 5: Ratings By Student Status

\begin{tabular}{|l|c|c|}
\hline Job Characteristics & Undergraduate & Graduate \\
\hline Benefits & 7.8 & 6.3 \\
City Size & 3.5 & 2.4 \\
Company Recognition* & 4.3 & 2.8 \\
Company Size & 3.7 & 2.7 \\
Ease of Commute* & 3.8 & 5.3 \\
Environmental Reputation & 2.4 & 1.7 \\
Geographical Region & 5.7 & 4.4 \\
Growth Potential & 8.6 & 8.0 \\
Job Responsibility & 6.8 & 7.7 \\
Job Variety/Complexity & 6.3 & 7.4 \\
Organization Type & 4.6 & 4.9 \\
Professional Dev. Programs & 4.4 & 5.9 \\
Social Responsibility & 3.3 & 3.2 \\
Stock Options & 5.9 & 5.6 \\
Training Classes & 3.9 & 5.0 \\
Travel Opportunities & 4.4 & 3.3 \\
Travel Requirements & 3.5 & 2.6 \\
Work Culture** & 5.2 & 7.7 \\
Work Flexibility* & 6.1 & 7.6 \\
Work Style & 5.6 & 5.7 \\
\hline
\end{tabular}

Note: $* *=p<.05 ; *=p<.10$

\section{Contributions}

\subsection{Implications For Practitioners}

Our findings have several implications for both corporate recruiters and university placement professionals. Corporate recruiters will be well-advised to package their offers so that they focus on characteristics that are deemed to be persistently important by students, such as potential for advancement and the nature of work (responsibility, variety, and complexity). Furthermore, they should tailor their offers (and overall recruiting strategies) to respond to the unique needs of specific business student groups. Specifically, the appeal of an offer to graduate students (especially female ones) can be enhanced by conveying the positive elements of work culture. The draw of a good location is likely to be most effective when recruiting male undergraduate students and least effective when targeting their graduate counterparts and female applicants. Company recognition may help sway undergraduate students, but graduate students are more interested in quality of life issues. Unquestionably, managers who take into account the above differences are likely to be more effective in their recruiting efforts. Recruiters may also increase their effectiveness by continuously reviewing new surveys of job preferences so that they can spot any changes in the attitudes of applicants in a timely manner.

University placement professionals can enhance the effectiveness of their services by enlisting employers that can satisfy the top preferences of their students (in terms of advancement potential, work responsibility, variety and complexity and other highly valued attributes). Also, when targeting specific student groups, it would be wise for them to enlist recruiters that can better satisfy the unique needs of their student population. For example, a placement office serving only MBA students should attempt to enlist recruiters that can effectively address the quality of life concerns that are important to such students. Finally, our list of the most desirable attributes could be used as a guide for the development of more localized surveys that are frequently administered by placement offices. To improve the effectiveness of such surveys, they should only include questions related to the most important core attributes and those most relevant to the subpopulation to be surveyed, as identified in our work (instead of including all attributes). This will allow the placement professionals to design shorter, more focused surveys to improve their efficiency and response rates. 


\subsection{Implications For Researchers}

As the job preferences of students constantly change (in response to specific events and market conditions), it is important for researchers to frequently survey students using reliable methods. The consistent use of job attribute lists, multivariate statistical techniques, and sophisticated evaluation procedures (such as the ones used in our study) should be effective in reducing reliability and validity threats in future studies. For researchers who wish to be more focused with their surveys (by just including a few select job attributes in them and using simple rating methods), our work would allow them to select a core group of enduring, important attributes (top 5 listed in table 3, for example) and supplementing them with a few other emerging or drastically changing attributes (such as stock options) to evaluate their relative importance. Based on previous work (Flynn et al. 1990, van der Pligt et al. 2000), it appears that such studies could use simple evaluation methods for up to 10 attributes without overloading the evaluators. By combining the core attribute sub-list with a few other attributes (that may change from year to year), such studies could efficiently and reliably provide current updates on the changing student preferences.

Our work has contributed to the cumulative body of research by reinforcing the importance of advancement potential and nature of the work. As a refinement on previous research, we noted an interaction effect between gender and experience level, providing further insight into the complex nature of these important factors. We believe that our sophisticated preference elicitation and more exact statistical techniques have contributed to the identification of this indirect effect (which has been overlooked by the simplistic techniques in prior studies). Given the complex nature of such effects, researchers must be more vigilant in their examinations by creating more comprehensive models of factors affecting job preferences and using advanced techniques to fully consider them.

\section{Conclusion}

By monitoring students' preferences and understanding the effects of individual characteristics on such preferences, recruiters and university administrators should be better equipped to tailor their messages and services to address the unique and changing needs of their job applicants. It is our belief that our study has contributed to the enhancement of such an understanding by utilizing reliable measures to confirm the importance of previouslyidentified job attributes and by shedding more light into the complex, non-linear effects of individual traits. While the currency of our results has a limited shelf-life, our study has provided a set of methodological tools that can be used in future studies to dependably track changes in the students' future preferences.

\section{Endnotes}

1. While the list of attributes that was used in our analysis is extensive (20 job characteristics were included), we decided to limit our focus to non-salary related job characteristics. Consistent with the arguments of Catalanello, Wegener \& Zikmund (1978), we view salary as an offer "qualifier". A salary level below a threshold amount will act as a deterrent to job offer acceptance, but a higher salary above a threshold does not increase the probability of acceptance. That is, up to a minimum salary level (a 'hurdle' level), compensation strongly outweighs all other job factors. As long as the acceptable minimum pay level is offered, however, any additional increase in pay will have little or no influence on the job selection decision and other factors become the determinants for it (Rynes, Schwab \& Heneman 1983).

2. To address the possible effects of presentation order on the participants' evaluations (Wanke, Schwarz \& Noelle-Neuman 1995) two versions of each questionnaire were developed and were randomly distributed to the participants. The first version presented the triads in a specific, randomly-determined order. The order of the triads was reversed in the second version.

3. To conduct the statistical analysis, the SPSS GLM procedure was used. Multivariate significance levels were assessed using the Pillai's Trace statistic, as our sample cell sizes were unequal. While testing the assumptions of the MANCOVA analysis, we found that the assumption of multivariate normality was violated as some Kolmogorov-Smirnov and Shapiro-Wilk tests were found to be significant. However, MANCOVA tests are known to be robust to violations of normality (Field 2000). Equality of covariance was tested using Levene's Test; Box's test was not used, as it is very susceptible to violations of normality (Field 2000). Although the results indicate that the data for 2 (out of 20) dependent variables violated this 
assumption, given that Pillai's Trace is relatively robust to assumption violations (Field 2000), this was not a significant concern.

\section{References}

1. Bottomley, P.A., Doyle, J.R. \& Green, R.H., "Testing the Reliability of Weight Elicitation Methods: Direct Ratings Versus Point Allocation,” Journal of Marketing Research, Vol. 37, No. 4, pp. 508-513, 2000.

2. Browne, B.A., "Gender and Preferences for Job Attributes: A Cross Cultural Comparison," Sex Roles, Vol. 37, No. 1/2, pp. 61-71, 1997.

3. Bundy, P. \& Norris, D., "What Accounting Students Consider Important in the Job Selection Process," Journal of Applied Business Research, Vol. 8, No. 2, pp. 1-6, 1991.

4. Butler, S.A., Sanders, D.E. \& Whitecotton, S.M., "Student and Recruiter Insights on the Importance of Job Attributes," Journal of Managerial Issues, Vol. 12, No. 3, pp. 337-351, 2000.

5. Cable, D.M. \& Judge, T.A., "Pay Preference and Job Search Decisions: A Person-Organization Fit Perspective," Personnel Psychology, Vol. 47, No. 2, pp. 317-348, 1994.

6. Carcello, J.V., Copeland Jr. J.E., Hermanson, R.H. \& Turner, D.H., "A public Accounting Career: The Gap between Student Expectations and Accounting Staff Experiences," Accounting Horizons, Vol. 5, No. 3, pp. 1-11, 1991.

7. Carpenter, C.G. \& Strawser, R.H., "Job Selection Preferences of Accounting Students." Journal of Accountancy, June, pp. 84-86, 1970.

8. Catalanello, R.F., Wegener, S.M. \& Zikmund, W.G., "A Career Choice Experiment," College Student Journal, Vol. 12, pp. 310-319, 1978.

9. Cotterman, R.L., "How Recent Graduates View Their Jobs," Research Technology Management, Vol. 34, No. 3, pp. 35-39, 1991.

10. Field, A., Discovering Statistics Using SPSS for Window, Sage Publications, London, 2000.

11. Flynn, B.B, Sakakibara, S., Schroeder, R.G., Bates, K.A. \& Flynn, E.J., "Empirical Research Methods in Operations Management," Journal of Operations Management, Vol. 9, No. 2, pp. 250-284, 1990.

12. Judge, T.A. \& Bretz, Jr., R.D., "Effects of Work Values on Job Choice Decisions," Journal of Applied Psychology, Vol. 77, No. 3, pp. 261-271, 1992.

13. Kirsch, R.J., Leathers, P.E. \& Snead, K.C., "Student versus Recruiter Perceptions of the Importance of Staff Auditor Performance Variables," Accounting Horizons, Vol. 7, No. 4, pp. 58-69, 1993.

14. Konrad, A.M. \& Langton, N., "Sex Differences in Job Preferences, Workplace Segregation, and Compensating Earning Differentials: The Case of Stanford MBA's," Academy of Management Best Papers Proceedings, Vol. 51, pp. 368-373, 1991.

15. Konrad, A.M., Ritchie, J.E., Lied, P. \& Corrigall, E., "Sex Differences and Similarities in Job Attribute Preferences: A Meta Analysis," Psychological Bulletin, Vol. 126, No. 4, pp. 593-641, 2000.

16. Lathan, M.H., Ostrowski, B.A., Pavlock, E.T., \& Scott, R.A., "Recruiting Entry Level Staff: Gender Differences," The CPA Journal, Vol. 57, No. 1, pp. 30-42, 1987.

17. McGinty, R. \& Reitsch, A., "Using Student Perceptions and job characteristics to recruit Recent Graduates," Review of Business, Vol. 14, No. 1, pp. 38-43, 1992.

18. Phillips, C.R., Phillips, A.S.\& Cappel, S.D., "Research Note: How Management Students Select Prospective Employers," International Journal of Manpower, Vol. 15, No. 1, pp. 55-60, 1994.

19. Pöyhönen, M. \& Hämäläinen, R., "On the Convergence of Multiattribute Weighting Methods," European Journal of Operational Research, Vol. 129, No. 3, pp. 569-585, 2001.

20. Rebele, J.E., Stout, D.E. \& Hassell, J.M., "A review of Empirical Research in Accounting Education: 19851991," Journal of Accounting Education, Vol. 9, pp.167-231, 1991.

21. Rebele, J.E., Apostolou, B.A., Buckless, F.A., Hassell, J.M., Paquette, L.R. \& Stout, D.E., “Accounting Education Literature Review (1991-1997), Part II: Students, Educational Technology, Assessment, and Faculty Issues," Journal of Accounting Education, Vol. 16, No. 2, pp. 179-245, 1998.

22. Robbins, R.R., "Attitudes and Perceptions of Computer Information Systems Students towards Employment Opportunities," Journal of Employment Counseling, Vol. 33, No. 2, pp. 61-70, 1996. 
23. Rynes, S.L., Schwab, D.P. \& Heneman, H.G. III, "The Role of Pay and Market Pay Variability in Job Application Decisions," Organizational Behavior and Human Performance, Vol. 31, No. 3, pp. 353-365, 1983.

24. Shirland, L., Jesse, R., Thompson, R. \& Iacovou, C., "Determining Attribute Weights Using Mathematical Programming." Working paper, School of Business, University of Vermont, 2002.

25. Simon, J. \& Kedslie, M., "What Are Recruitment Selectors Looking For?" Management Accounting: Magazine for Chartered Management Accountants, Vol. 75, No. 7, pp. 58-60, 1997.

26. Tolbert, P. \& Moen, P., "Men's and Women's Definitions of 'Good' Jobs: Similarities and Differences by Age and Across Time," Work and Occupations, Vol. 25, No. 2, pp. 168-194, 1998.

27. Turban, D. Eyring, A. \& Campion, J., "Job Attributes: Preferences Compared With Reasons Given for Accepting and Rejecting Job Offers," Journal of Occupational and Organizational Psychology, Vol. 66, No. 1, pp. 71-81, 1993.

28. Van der Pligt, J., de Vries, N., Manstead, A. \& van Harreveld, F., "The Importance of Being Selective: Weighing the Role of Attribute Importance in Attitudinal Judgment," Advances in Experimental Social Psychology, Vol. 32, pp. 135-200, 2000.

29. Wanke, M., Schwarz, N. \& Noelle-Neuman, E., "Asking Comparative Questions: The Impact of the Direction of Comparison," Public Opinion Quarterly, Vol. 59, No. 3, pp. 347-372, 1995.

\section{Appendix 1: List Of Job Attributes Included In The Questionnaire}

1. Benefits - health, dental, retirement, vacation, sick leave, tuition remission, relocation reimbursement, maternity/paternity leave, child care

2. City size - rural, suburban, urban

3. Company recognition - knowledge of company/brand name

4. Company size - number of employees, number of locations, annual revenue, market capitalization

5. $\quad$ Ease of commute - round-trip time required and potential stress involved

6. Environmental reputation - policies and track record in support of environmental issues.

7. Geographic region - country, area within country such as U.S. Northeast

8. Growth potential - opportunities for promotions, opportunities for personal growth

9. Job responsibility - ability to make a difference and/or influence change

10. Job variety/complexity - multiple tasks and responsibilities that change

11. Organization type - not-for-profit, government agency, manufacturing, financial services, public service, peace corp., etc.

12. Professional development programs - required, formal, multi-month/year program

13. Social responsibility - community involvement, supportive policies on alternative lifestyles, etc.

14. Stock options - opportunity to purchase ownership in the company at a given price

15. Training classes - short duration, specific topic training sessions

16. Travel opportunities - options exist for off-site assignments, either domestic or international

17. Travel requirements - frequent travel is an expected part of the job

18. Work culture - dress code, employee demographics, formal versus informal communications

19. Work flexibility - flexible work hours, opportunity to work from home, etc.

20. Work style - team versus individual, pace of work, level of human interaction

\section{Appendix 2: Partial Instructions To Participants}

Procedure: Rank each three-choice set according to the importance they should be given in choosing a company to work for after graduation. Refer to the Item Definitions List for clarification.

1. Work across the page. Judge only three choices at a time.

2. Decide which of the three you feel is "most important" among just those three. Place a " 1 " in the space to the left of that choice. There should be at least one score of " 1 " for every set of three on the questionnaire. 
3. Now, decide which is next most important. Make its score "2" if you judge it less important than the one you scored first. Make it the same score if you judge it to be equal in importance. Place the score in the space to the left of that choice.

4. Judge your third choice. Compare it to the one that was your second choice. Make the score of your third choice 1 point higher than your second choice if you judge it less important than your second choice. If it is equally important to your second choice, make it the same score as your second choice.

\section{Scoring Examples:}

\begin{tabular}{|c|l|c|l|c|l|}
\hline 1 & Growth Potential & 2 & Benefits & 3 & Ease of Commute \\
\hline
\end{tabular}

This response says "Growth Potential" is judged most important among the three choices. It is more important than "Benefits". "Benefits" is more important than "Ease of Commute".

\begin{tabular}{|c|l|c|l|c|l|}
\hline 2 & Growth Potential & 2 & Benefits & 1 & Ease of Commute \\
\hline
\end{tabular}

This response says "Ease of Commute" is judged most important among the three choices. "Benefits" and "Growth Potential" are judged to be equally important.

\begin{tabular}{|c|l|l|l|l|l|}
\hline 1 & Growth Potential & 1 & Benefits & 1 & Ease of Commute \\
\hline
\end{tabular}

This response says that all three attributes are of equal importance. 